\title{
The Kung Fu Family: A metaphor of belonging across time and place
}

\author{
Veronika PARTIKOVÁ1 (D), \& George JENNINGS² \\ ${ }^{1}$ Hong Kong Baptist University (China) \\ ${ }^{2}$ Cardiff Metropolitan University (UK)
}

Recepción: 29/05/2018; Aceptación: 03/06/2018; Publicación: 04/06/2018.

ORIGINAL PAPER

\begin{abstract}
Kung Fu associations are often understood as 'families' forming broader 'family trees' or lineages operating across centuries of history as well as transcultural associations. In an effort contributing to interdisciplinary martial arts studies, this paper presents data from two qualitative studies of Western practitioners of traditionalist Chinese martial arts (TCMA) in both the West and Asia by a phenomenological psychologist and an anthropological sociologist. We assess the use of the term 'Kung Fu family', what it means to the practitioners and how it impacts on their practice and their relationships with other martial artists. We argue that the conceptual metaphor of family offers a sense of belonging and solidarity within a diverse community in terms of age, ethnicity, gender, religion and social class. Meanwhile, we explore the metaphor in terms of the micro-political power dynamics that accompany martial arts collectives. Overall, the ideal of family can illuminate how identity can transcend across time ('generations' of practitioners) and place (from and to cultures and contingents). It is thus a way of understanding the organisation, spread and transcendence of Chinese martial arts.
\end{abstract}

Keywords: Collective identity; conceptual metaphor; Chinese martial arts; family; lineage; martial arts.

\begin{abstract}
La familia del kung fu: una metáfora sobre la pertenencia a través del tiempo y el espacio

\section{Resumen}

Las asociaciones de kung fu son entendidas, a menudo, como 'familias' que forman parte de amplios 'árboles genealógicos' o linajes, que vienen funcionando desde hace siglos, y también como asociaciones transculturales. Contribuyendo al ámbito de los estudios multidisciplinares sobre las artes marciales, este artículo presenta datos de dos estudios cualitativos sobre practicantes occidentales de artes marciales chinas tradicionales (TCMA), tanto en Occidente como en Asia, realizados por una psicóloga fenomenóloga y un sociólogo antropólogo. Hemos evaluado el uso del término 'familia del kung fu', lo que significa para los practicantes y cómo afecta a su práctica y a sus relaciones con otros artistas marciales. Argumentamos que la metáfora conceptual de la familia proporciona un sentido de pertenencia y solidaridad dentro de una comunidad diversa en términos de edad, etnia, género, religión y clase social. Paralelamente, exploramos la metáfora en términos de las dinámicas micropolíticas de poder que acompañan a los colectivos de las artes marciales. En líneas generales, el ideal de la familia puede iluminar cómo la identidad puede trascender en el tiempo ("generaciones" de practicantes) y el espacio (desde y hacia culturas y grupos). Por tanto, se trata de una forma de entender la organización, difusión y trascendencia de las artes marciales chinas.
\end{abstract}

Palabras clave: Identidad colectiva; metáfora conceptual; artes marciales chinas; familia; linaje; artes marciales.

\section{A família do kung-fu: uma metáfora sobre a pertença através do tempo e do espaço}

\section{Resumo}

As associações de kung-fu podem ser entendidas como "famílias", que formam parte de amplas "árvores genealógicas" ou "linhagens", que funcionam há séculos, e também como associações transculturais. Contribuindo para os estudos multidisciplinares sobre as artes marciais, este artigo apresenta dados de dois estudos qualitativos sobre praticantes ocidentais de artes marciais chinesas tradicionais (TCMA), tanto no Ocidente como no Oriente, realizados por uma psicóloga fenomenologista e um sociólogo antropólogo. Avaliamos o uso do termo "família do kung-fu", o que significa para os praticantes, como afeta a sua prática e as relações com outros artistas marciais. Argumentamos que a metáfora conceptual da "família" proporciona um sentido de pertença e de solidariedade dentro de uma comunidade diversa em termos de idade, género, etnia, religião e classe social. Paralelamente, exploramos a metáfora em termos das dinâmicas micropolíticas de poder que acompanham os coletivos das artes marciais. Em linhas gerais, o ideal da família pode elucidar como a identidade pode transcender com o tempo (gerações de praticantes) e o espaço (cultura e grupos). Para tanto, trata-se de entender a organização, difusão e transcendência das artes marciais chinesas.

Palavras-chave: Identidade coletiva; metáfora conceptual; artes marciais chinesas; família; linhagem; artes marciais.

${ }^{1}$ Hong Kong Baptist University. Baptist University Road. Kowloon Tong, Hong Kong. E-mail: vpartikova@gmail.com 


\section{Introducing the Kung Fu family}

I ended up getting close to, obviously, the sort of black belts at the time...we had a whale of a time [lots of fun]...cos we were mates...Rick [his Kung Fu senior] became a very close friend of mine, even though you know, a lot of people wouldn't give him the time of day sometimes just by looking at him. You find out he's one of the nicest men in the world, and he's like a brother. It's good to have that, because it's more of a family than a club, you know?... At the end of University, all my mates started to wander off, but I wanted to stay just to do Kung Fu...as a result my only sort of social arrangement was by going to Kung Fu...So in Adderton [home of the branch Kung Fu school], the only people I knew were Kung Fu people. As it turns out, they're still pretty much all I know, if I was going to have a drink with somebody, it would probably be someone from Kung Fu...it was how it was...It became my only sort of source of friendship...I had no family close by... So I wanted to get involved and find friends that would help me out I suppose, emotionally, which was interesting. (Sifu Steve, Wing Chun instructor).

This extract (with our emphasis on metaphorical and familial expressions in italics) came from a life history interview that George Jennings conducted in 2006 with Sifu (teacher) Steve, a British Wing Chun practitioner-instructor who formed part of a local Kung Fu association studied as part of a five-year ethnography (see Jennings, Brown, \& Sparkes, 2010). This interview stimulated the beginning of an analysis of core metaphors of journey, metaphor, family and discovery as the study extended to a PhD (Jennings, 2010). Yet it also resonates with numerous other interviews facilitated by Veronika Partikova (in press a, in press b) in her transnational study of Kung Fu practitioners' identities in various associations. Steve's words display a manner of conceptualizing such Kung Fu associations, clubs and its core members in terms of a family. It is important to note that Steve was from a different part of the UK, and had relocated in order to study at university. Yet he remains in this region to his affinity for his peers and deep loyalty for the Kung $\mathrm{Fu}$ association and his particular lineage - a rare one in Europe. It is also notable that none of the Wing Chun exponents in his Kwoon (school) are actually a 'brother' or 'sister' in blood or adoptive terms, but are people from a variety of social class and occupational backgrounds, as well as ages spanning across chronological generations. One younger brother might be a Swedish dentist in his 60s, while a senior sibling might be a reformed criminal. His 'Kung Fu brothers' - as the group is predominantly male - comprise of former bouncers, entrepreneurs, academics, students and manual workers, and include young women, middle-aged men and retirees. Like the migrant restaurant workers in Kim's (2009) ethnographic study, Steve found a sense of belonging through this new 'family' in Kung Fu, regardless of their origin.

So what is this 'Kung Fu family', and how does it operate in a manner of conceptualizing the Chinese martial arts by non-Chinese, Western practitioners? With the aim of understanding the meaning and expressions given to the conceptual metaphor of Kung Fu family, this article explores this phenomenon through a primary focus on in-depth interviews with Western Kung Fu exponents based in various countries in East Asia and Europe, along with an assessment of related observations and documents. As a collaborative venture combining the data from two separate yet similar studies, it sheds light on the unexplored yet crucial element of family in the traditionalist Chinese martial arts (TCMA). In order to understand the Kung Fu family in contemporary and transcultural societies, it is first important to situate the TCMA in a historical and anthropological perspective from their native land and through the Chinese diaspora using the work of interdisciplinary scholarship in martial arts studies (see Bowman, 2015, forthcoming). We then explain the Conceptual Metaphors (drawing on Lakoff \& Johnson's 1980, 1999 well-established framework) as a way of thinking, acting and being-in-the-world, which guides our theoretical analysis. Following an account of our separate projects and positions, we then explore and deconstruct the conceptual metaphor of family through its subcomponents of: a) lineage as family tree; b) schools as home; c) club as family; d) teacher as father, and e) classmates as siblings. Our article therefore examines certain places such as the Kwoon and then the core members of the Sifu/Shifu ('teaching father'), Sihing ('elder sibling') and other fictive-kinship relationships. This guides our core argument set out in the conclusion: that the Kung Fu family is a way of understanding, sustaining, reproducing and evolving Kung $\mathrm{Fu}$ across successive generations and 
places in the world. When then close by considering that the metaphorical mapping of Kung Fu-asfamily not only helps us understand Kung $\mathrm{Fu}$, but also helps us question the very notion of family itself - a topic for further research through the anthropology and sociology of the family in particular. First, however, we dissect the term 'Kung Fu family' in a historical and linguistic sense.

\section{Kung Fu across time and place}

The history of the Chinese martial arts styles is now well documented, as it can often be traced back to clan villages, where the practice of genealogy was upheld until the Cultural Revolution (Wile, 2018). Real Kung Fu families (in terms of inter-marriage and kinship relationships) have therefore existed across dozens of generations. Although with numerous cultural, economic and political shifts, the ideal of Kung Fu family now exists outside the home regions of their origins and across a much wider ethnic, linguistic and class backgrounds. Indeed, certain systems such as Wing Chun, the one Sifu Steve teaches, has transcended such barriers with its continuous adaptations in societies (Judkins \& Nielson, 2016). Notwithstanding the long and widespread tradition of TCMA practice, there is an ongoing discussion about the usage of the modern term 'Kung Fu.' Since the term literally means "profound notion referring to moral edification obtained through long-standing wushu training" (Zhang, 2014, p. 156), or simply put as "skill achieved through time and effort" (a quote we have encountered as practitioners), it is argued that its connection with martial arts is misleading. An academic could have Kung Fu in writing, for instance. But those who use this term actually mean to emphasize the effort and time investment, the mastery rather than goal orientation. Moreover, Judkins (2016) indicates that Kung Fu, as opposed to Wushu, is an expression associated with particular historical development and heritage, and most importantly contains the disagreement with the new sport movement of modern Wushu:

The current use of the phrase kung fu is not, as so many popular sources have claimed, the result of gross ignorance by western students. It was first applied to the martial arts by Chinese practitioners who were looking for a new vocabulary to explain their practice in the early 20th century. (Judkins, 2016, p. 2).

While "Kung Fu" is a term associated with martial arts by many in modern societies, its meaning may be unclear. Commonly, Kung Fu is incorrectly perceived as a naming for a specific (Chinese) martial art style, as for example it is with Japanese Judo - a singular martial art and combat sport practiced under one governing body. Understanding of the definition is foggy and so is the picture of the training community in the contemporary age, especially as there exist a number of terms across a range of Chinese languages (such as Cantonese, Mandarin and Hokkien) and throughout historical periods (from Ancient China to the Chinese diaspora today). However, the Chinese martial arts in general are nowadays called either Kung Fu or Wushu. Wushu as a modern (sporting) expression following many terms, such as Gung Fu or Gong Fu in Cantonese (see Theeboom \& DeKnop, 1997, for an extensive historical discussion). Although these names may overlap or merge sometimes, in other cases, they are each other's opposite. Wushu literally means "art of war" or "martial art" (Wildish, 2000) and can be understood as a Chinese sibling of the Japanese "Budo". There are two extensive categories of Wushu: the sport discipline which is competition oriented with simplified martial movements and added jumps and acrobatics, called modern Wushu. And its original ancestor, with direct movements focused more on civic and military fighting, self-defense, as well as personal and collective growth: traditional Wushu. Kung Fu is commonly used to refer to traditional Wushu (Wang, Qiu, \& Bao 2010), and it is this latter approach to TCMA that we focus on in this article.

Inside this traditional Kung Fu, there are dozens of systems, many of which have their own styles, specific lineages and associations, much like other Asian martial arts such as Kalarippayattu, which is often run by real-life families in their villages (Zarrilli, 1998). There is no unifying governing body of Kung Fu, even within smaller entities or nations such as Hong Kong or Britain. As Allen (2013) notes on Asian martial arts in general, they can be sports, but are not games, and might be aesthetically pleasing, but are not pure works of art or dance. Sometimes (and frequently in the popular literature), they are divided according to other dichotomies, such as according to their geographical origin: northern styles and southern styles, for example. The systems may also 
be split into 'hard' and 'soft', 'inner' and 'outer' martial arts. This is because of technical differences, and also trends in organisation and political influences. Following such as dualistic classification system, for example, Taijiquan (better known as Tai Chi or Tai Chi Chuan) is often cited as an example of inner styles and Wing Chun of outer styles. However, this definition is overly simplistic, based on the fact that it is impossible to split soft and hard, as these principles come together and create balance (the embodied yin-yang duality explained in Brown, 2016), and styles can neither contain nor work with hard or soft principles only. Finally, some scholars such as Wang et al. (2010) tried to list 'families' of Kung Fu (Shaolin, Wudang, Emei, Nanquan, Taijiquan, Xingyiquan and Baguazhang), but the list may not be exclusive. The taxonomy is further complicated by the fact that there are a number of variations within each style, according to the approaches of specific master practitioners and their innovations as martial artists - the beginning of what are also known on the local level as families.

Despite this debate, some researchers note a particular phenomenon in terms of the Southern styles of Kung Fu, many of which, as Farrer (2011) has accounted for, have spread across the Chinese diaspora to places such as Singapore and Hong Kong as esoteric or secretive organisations led by elderly masters. Farrer (2018, p. 38) further observes: "Southern Chinese martial arts share origin myths and a performative tradition of cult-like rituals to enter discipleship to specific masters, pledging oaths of lifelong, exclusive allegiance." It is these southern systems and their particular stylisations through families (as seen in Wing Chun, Hung Kuen, Chow Gar, etc.) that we focus on in this particular article. Significant for our paper is the connection with both history and culture of China, which binds Kung Fu with some roles, settings and group organisation based on Chinese philosophies. The role and organisation of family is incredibly important, and especially in the traditional Chinese society it is a very tight and strong relationship. Sifu (Cantonese) or Shifu (Mandarin) may be interpreted as a 'teaching father,' an adoptive and chosen family that people like Sifu Steve chose to stay with and nurture.

Our paper is therefore focused not only on the stories of individuals, but on the social group around the individual practitioner, and the sense-making involved through language. The importance of a community can be seen in many other physical cultures. Evans, Eys and Wolf (2013) stated that people around an athlete are the main source of motivation and social facilitation. Furthermore, Even, Eys and Bruner (2012) stated that dividing sport into individual and collective is outdated and unprecise. Similarly, Kung Fu also creates a community around their members, however this group can be very specific when comparing to sporting communities. The relationships are family-based, which means there is a hierarchy (parent - children), rather than a militaristic one. As Vlachos (2015) observed, there is a reciprocal solidarity: the older students help the younger ones, and the younger ones look up to their elders. Vlachos (2015) also noted that competition in the group is restrained, which is logically based on the system of relationships. Instead, as in other traditionalist Asian martial arts, cooperation is highlighted and so the students learn how to respect each other and foster the whole group (see Layton, Higaonna, \& Arneil, 1993). Kennedy and Guo (2005) note that this is how Kung Fu survived and was passed down generations, although they later identify a turning point in the development of international associations such as the Jingwu Athletic Association, which spread from Shanghai to across the world (Kennedy \& Guo, 2010).

Despite continued changes and diffusions across the world, and well-known adaptations in certain modalities to Taijiquan as a predominantly health and meditative and even performance art (Mroz, 2008; Ryan, 2008), Kung Fu remains primarily what Brown and Johnson (2000) term a selfdefence martial art, a physical exercise where partners touch each other and may get into sensitive, yet negotiated positions inter and intra-sex positions (Channon \& Jennings, 2013), which is also a good representation of the cooperative principle. This is common in other forms of martial arts, such as Mixed Martial Arts (MMA), as seen in Spencer's work (2013), and in Capoeira, where loyalty to one teacher is seen as paramount - both in Brazil (Downey, 2004) and overseas (De Campos Rosario, Stephens, \& Delamont, 2010). The reverse of this is the devotion of the teacher, as Alter's (1992) seminal study also showed the importance of the guru figure, who often dedicated their lives to wrestling. Similarly, Green (2011) observed this kind of common bodily training experience can produce strong friendship based on trust, similar to a brotherhood. More recently, Pedrini's (2018) study of unlicensed boxing among leftist groups in Italy found a sense of brotherly 
fraternity. In the TCMA, in countries like Britain, people of any kind of background, education, or status, when they enter the school, become one of the family member. The common goal of idealized 'perfection' of the specific Kung Fu system like Wing Chun creates a strong connection between people, who otherwise follow different interests (Jennings, Brown \& Sparkes, 2010) and pursue TCMA in slightly different ways (Brown \& Jennings, 2013) under diverse pedagogies and through creative yet subtle methods (Girton, 1986). This is related to embodied knowledge developed through specific 'body lineages' (Brown \& Jennings, 2011), through its members and via specialist objects found in the training pedagogy (Domaneschi, 2016) and the specific forms of power relationships contained within them, as Nulty explains:

In many traditional Chinese martial arts, gong (or skill training) was reserved for the master's disciples. Discipleship in Chinese martial arts at times has the status of an adoption where the discipline-master relationship is identical to that of father and son. (Nulty, 2017, p. 51).

Furthermore, works by Frank $(2006,2014)$ on Taijiquan in China exposed the continued observation of "closed door" traditions in which people from outside are not able to access information inside the family-based style. However, this can be overcome by belonging to a specific teacher reflects strongly one's status in the community and serves as a key to open certain doors (literally and non-literally). Finally, being a member of the community brings a specific status. Frank (2014) explored this in a case of a Taijiquan teacher as a protector and keeper of knowledge, who decided to teach certain 'hidden' techniques to his students. The resulting conflict among him and his seniors was a form of defense of the status of belonging to the Kung Fu family or not. According to the seniors, he was not allowed to teach the advanced techniques to outsiders without permission. Here, the status of 'insider' or 'outsider' - quite marked when compared with the fluidity seen in boxing (Woodward, 2008) - decides if the individual can reach the information and be taught. Being a member of a Kung Fu lineage serves as a credential, bridging a gap between two strangers who meet for the first time, based on the trust that the practitioners' seniors (the lineage) grant to them. Before exploring the father-son relationship, the themes of closed and open door students, and those that bind them together within a broader family and family tree, it is necessary to portray them in terms of a conceptual metaphor: a way not just to talk about martial arts, but to think about them in terms of one's own flesh and blood.

\section{Theorising Metaphor}

Metaphors, just likes Kung Fu, are commonly misconceived. Quite often, people think of metaphors as poetic expressions carefully (and thereby quite consciously) selected by scribes and literary artists, rather than as socio-cultural foundations of language and thought. The widely cited Metaphors We Live By (Lakoff \& Johnson, 1980) changed the academic perception of this through their Contemporary Theory of Metaphor, which began to be seen as not just a manner of speaking (and writing), but a way of thinking (and being). Metaphor, or understanding and expressing one phenomenon in terms of another, was studied in terms of sociolinguistics and psychology, and the authors shared a range of metaphorical linguistic expressions (MLE) that are manifestations of deep-rooted conceptual metaphors. For example, life-as-a-journey is a common metaphor seen in a variety of cultures across the world, and is portrayed for analytic and representational reasons as the capitalised LIFE IS JOURNEY. By seeing LIFE (the source domain) in terms of a JOURNEY (target domain), one is permitted to express and immediately comprehend utterances such as: "You're going nowhere fast!" (when a person is not developing as expected) or "We've had our ups and downs" (a shared experience of joys and difficulties in life) or even "I'm at a crossroads" (when provided with important decisions to make, such as in a career) and "There's no turning back now" (having made a decision). In fact, the reader of this article probably does not require our explanation in parenthesis, unless they are unfamiliar with some of the words in English. They will also notice that the words 'life' and 'journey' do not appear in this expressions, and the source and target domains may remain silent or taken-for-granted, being extracted from the interactive social context. Meanwhile, none of those sentences (the MLE) need to refer to actual movement in any direction or pace, but at instantly understood and can be transmitted and interpreted by a variety of listeners and readers. In short, we think through metaphors and make sense of the world 
through them. The expressions are rendered in italics, as Lakoff (1992) demonstrated in his breakdown of the theory using such metaphorical mapping of love-as-journey.

From these examples, one can perceive the way in which people think through metaphor, and might try out other thought experiments of their own in terms of other common conceptual metaphors such as LOVE is WAR also explored in Lakoff and Johnson's (1980) extensive analysis. Nonetheless, their work might seem overtly cognitive in the emphasis on thought over action. In their later work, Philosophy in the Flesh, Lakoff and Johnson (1999) began to see the role of the body and embodiment in conceptual metaphors to bolster the Contemporary Theory of Metaphor. With many metaphors using movement and physical interaction in their relationship between the source and target domains, it became clear that the body is used a universal form of communication as in: "You're going down" and "The only way is up." Both are readily understood: 'down' being equated with failure, loss and decay; and 'up' being, quite literally, upbeat and positive about the future. Metaphors express the values and ideas of a culture, and many, due to our embodied makeup, are cross-cultural. This theory has been tested and applied in other languages aside for the original English, such as in China. One study (Yu, 2003) found the same core metaphors (such as LIFE IS JOURNEY) in Chinese culture and language, but also different ways of perceiving the body and other aspects of life. But specific metaphors in subcultures originating in China, such as in Kung $\mathrm{Fu}$, have not yet been explored to see if they offer alternative understandings of everyday relationships (such as the family) or aspects of culture (the martial arts).

Notwithstanding this gap in knowledge, the Contemporary Theory of Metaphor and metaphorical data have been applied and critiqued within a range of contexts by scholars in sports studies, dealing with topics from politics perceived as sport (e.g. Samino \& Masci, 1996) to mediated interpretations of national success and loss (Von del Lippe, 2002). Much of this has shown a deliberate use of metaphor (especially those emanating from politicians), as well as subconscious reproduction, which indicates that conceptual metaphors, although constructed by language and society, are actively reconstructed and reconstituted by the agents that form the society or group in question. It has also interested researchers looking at sport, as sport itself is often conceptualized within metaphors (such as CONTEST IS WAR, seen in Shields \& Bredemeier, 2011), and is also subject to a range of MLEs that illuminate particular sport and physical cultures. Meanwhile, the role of the body is ever prominent in sport, and is tied to narratives and general talk. The work of Smith and Sparkes (2004) provides a notable example of metaphor analysis in sport, in which they assessed the stories of men who had suffered spinal cord injury (SCI) in Rugby Union. The majority of these men used bodily metaphors perceiving their disability as an entity to fight and resist. Yet some others offered alternative metaphors connecting to more open-ended narratives of life seen as a journey.

In combat sports, the article "Whores, slaves and stallions" by Wacquant (2001) provides some insightful data on what he calls 'idioms', in terms of exploitation of boxers in the United States from a Marxist perspective. Wacquant shared idiomatical expressions of prostitution, slavery and animal husbandry respectively, and showed how the boxers made sense of them in metaphorical ways, although this study did not make overt use of metaphorical analysis. Besides this article, to date and to our knowledge, no published study on traditional martial arts has overtly used the Contemporary Theory of Metaphor or metaphor analysis as a theoretical and methodological guiding point. There have been efforts to incorporate this approach into a wider study by Jennings (2010), who identified core metaphors of LIFE IS JOURNEY, MARTIAL ART IS RELIGION, LEARNING IS DISCOVERY, and GROUP IS FAMILY in his analysis of British practitioners of Chinese martial arts and their life stories of learning, growth and challenges encountered over the years and decades of experience. This leads us to account for our continued analysis of the final conceptual metaphor, the family, using this study, the previous ethnography and an emerging investigation from Veronika Partikova.

\section{Metaphor as Method}

The data which we present in this paper come from the cooperation of two researchers, and is thus a joint analysis based on shared data sets from two different studies. This has been achieved by Channon and Jennings (2013) in relation to mixed-sex martial art training experiences and 
Channon and Phipps, (2017) with their combined findings on women's experiences of combat sports. While George Jennings set up interviews and observations with British TCMA practitioners in England (2006-2010), Veronika Partikova worked in Hong Kong (2015-18). In both cases, they focused on English-speaking Europeans who have a significant experience in traditional Kung Fu. We united after meeting at a conference where Veronika delivered a paper concerning the transferability of Kung Fu family to the West. Having studied this topic as part of a broader study, George saw the collaboration as a fruitful endeavor in terms of combining data and working with metaphors, which are both psychological and sociological in nature.

Despite our different regions and timeframes, we approached the phenomenon of Kung Fu family in strikingly similar ways. Veronika is a Czech female PhD student in her late twenties who is based in Hong Kong, where she is finishing her doctoral thesis on mental toughness and psychological collectivism in TCMA. Her previous study looked at the experiences of European Kung Fu instructors, which extended to follow the psychological theories of Triandis (1995) and the approach of Interpretive Phenomenological Analysis (IPA) seen in Partikova (in press a) and also in relation to mental toughness, found in Partikova (in press b). This theory resonates with the metaphor of KUNG FU IS FAMILY in the sense that Triandis (1995) stresses that humans hold a tendency to form (and be attracted to) closely-knit groups. This gives them preference for consensus and solidarity and understanding hierarchy and oneself as changeable in a stable environment. Veronika is also a seasoned Hung Kuen practitioner, with 15 years spent in Karate and various styles of Kung Fu. She has recently undertaken the master-discipline ceremony with her own Sifu, and is now an 'indoor' student of his school. With such a background, she has a high standing in TCMA, and also competes for her country on regional and international circuits.

In her doctoral study, Veronika conducted eight in-depth interviews, and participant observations during her fieldwork in China and Europe (precisely Czech Republic, England and Georgia). The eight participants were contacted through a snowball sampling technique in the setting of Hong Kong, as they either live in Hong Kong or they regularly come to visit the island as part of their training. Two of them she knew personally, the others were referred and so was she as a researcher. Through this recommendation and networking, she could find people with a rich practice experience and willingness to join the research. Veronika's interview participants were six men and two women, coming from the Czech Republic, Germany, Ireland, the Netherlands and Spain. The oldest participant was 69 years old, while the others were in their $30 \mathrm{~s}$ or $40 \mathrm{~s}$. The specific styles they practiced were: Bak Mei, Choy Lee Fut, Hung Kuen, Long Jing, Taijiquan, Tang Lang and Wing Chun. Four of them lived (or still live) in China, another one lived in the Chinatown of San Francisco, while two men are currently full-time professional Kung Fu instructors. Besides the interviews and personal experience, participant observations were done during the training sessions with the participants and in other schools and training centers Veronika visited during her multi-cited fieldwork. Each of the interviews was around 90 minutes long and focused on three main topics: the training, the community, and the outcome to the everyday life. Veronika encouraged the participants to tell stories and so the interviews were very narrative based. All the interviews were audio recorded, except for one, where the participant did not feel comfortable about it, so Veronika handwrote the transcript directly.

George is a British male lecturer, aged 33, with a background in exercise and sport sciences and the sociology of sport. As an academic nomad, his work has shifted from a sociological focus to one leaning towards anthropology. His investigations began with an ethnography of a British Wing Chun association (published in Jennings, Brown \& Sparkes, 2010), which also involved two life history interviews. This later extended to a PhD thesis involving life history interviews with 16 long-term practitioners of TCMA in the UK (Jennings, 2010; Brown \& Jennings, 2013). These martial artists were British citizens hailing from different parts of the UK, with one being Hong Kong Chinese, and three being female. Their ages ranged from 24 to 68, with experience in TCMA spanning from the minimum of four years all the way to three decades. Each participant was interviewed twice (apart from one person for practical reasons), with interviews totaling between two and three hours per person. The focus on narratives and elaborate life stories was extended to incorporate an analysis of online and document sources (Jennings, 2014; Jennings, Brown \& Sparkes, 2014). 
Like Veronika, George is a practitioner-researcher; he has been practicing various Asian martial arts since 1998, including Taekwondo, Judo, Kendo and various styles of Taijiquan, and is a qualified instructor of Wing Chun Kung Fu, having started the art in 1999. He has since studied other martial arts such as those from Mexico, and has returned to research on TCMA with a fresh and increasingly critical perspective. An undisputable advantage for both of us was that we were already inside the field of TCMA in our respective regions at the time of data collection, and thus did not need to enter as newcomers. Our own training status bestow us credibility and won trust among the interview's participants. The Kung Fu community is rather closed and tight; people know each other and their recommendation has weight. However, due to our insider status as trusted members of this community, we were sure to observe ethical conventions of informed written and verbal consent with those who we formally interviewed and observed, obtained ethical permission from our respective universities, and provided transcripts and notes from our interviews to check over with the interviewees. All these participants were given pseudonyms to protect their own identities and those around them in their Kwoon, association and lineage.

The findings we present are grounded in these data and the emerging topics. We first shared our data identified as being relevant to the theme of Kung Fu family. During the dual analysis process, we applied hierarchical coding and searched for topics which came directly from the data, not from any hypothesis. The relationship of the codes was based on abstraction, polarization, contextualization or other kinds of connections (Flowers, Larkin \& Smith, 2009) and the procedure was similar to a free text analysis (Smith \& Osborn, 2003). Our main focus was the Kung Fu family, which has already investigated in the interview process by directing the topic by the questions we asked. We wanted to research how the Kung Fu family was understood through the metaphor methodology and how this metaphor was used and created. Inspired by the detailed metaphorical work with narrative-based data seen in interviews and life histories (Smith \& Sparkes, 2006; Stewart, Smith \& Sparkes, 2011) we followed Lakoff's (1992) guidance of developing the kung fu-as-family mapping, and have broken it down into distinct and jointly identified components. With such plentiful interview data totaling at 24 participants (the majority of whom spoke of the Kung Fu family), we had to select certain voices to be shared and those to be silenced for reasons of space. For that reasons, certain characters were chosen to provide expressions of the Kung Fu family, showing their relationships with those around them, and, in the case of the ethnography, with each other. Within the next section, then, we offer the representation of MLEs as seen through some long-term and ongoing ethnographic data (from George), but chiefly the recent international cohort from Veronika's study.

\section{Analysis: Deconstructing the Kung Fu Family}

In this more extensive section, we share our deconstruction of the member-identified term of Kung Fu family as a conceptual metaphor (KUNG FU IS FAMILY) through its constitutive parts using data from our interviews, observations and ethnographic conversations, as well as core documents stemming from our sites of practice and fieldwork. For reasons of logic - from the theme of history and time (lineage) to the most embodied, quotidian, interactive and fraternal relationships in immediate physical space (brotherhood and siblings) - we structure the discussion in the following order of six sub-metaphors:

1) LINEAGE IS FAMILY TREE;

2) SCHOOL IS HOME;

3) CLUB IS NUCLEAR FAMILY;

4) TEACHER IS FATHER;

5) CLASSMATES ARE SIBLINGS;

6) KUNG FU IS RELATIONSHIP.

This is also logical in the sense that one requires a lineage of have pedigree in order to enter a new school and become an indoor student, which in term permits the advancement to Sifu level, which is assisted by the pedagogy of older brother and sisters supporting the general sense of brotherhood and fraternity. Following convention observed from Lakoff (1992), all parts in italics were added with our own emphasis on the individual MLEs. 


\subsection{Lineage is family tree}

In Chinese martial arts society, the ranking system follows the traditional family system. Classification of higher or lower level students is not based on one's skill or actual age, but is decided by who joins the school first. For example, your teacher (male or female) is your father within the system. You should greet him as "SI-FU" (meaning teaching father) to show respect. Your older brother, regardless of age, would be addressed as "SI-HING." The following are some terms that explain the relationship in the gung fu ranking system:

- SI-JOU: An ancestor within the system

- SI-GUNG: Your teacher's teacher, as your grandfather

- SI-BACK: Your teacher's SI-HING, as your uncle

- SI-SOOK: Your teacher's SI-DAI, as your uncle

- SI-FU: Your teacher (male or female), as your father

- SI-MO: Your teacher's wife, as your mother

- SI-HING: A male classmate you joined the school before you, as your older brother

- SI-JE: A female classmate who joined the school before you, as your older sister

- SI-DAI: A male classmate who joined the school after you, as your younger brother

- SI-MUI: A female classmate who joined the school after you, as your younger sister.

(Master Li's book).

The above extract comes from a core text of Bridge's Wing Chun Association, as it is written by Sifu Bridge's own Sifu, Master Li. A renowned expert in the system based in the United States (yet originally hailing from Macao), Li is better known for his skills than his writing prowess, and this remains his only book in half a century of engagement in the art of Kung Fu. The book is on display in the reception area of Church Kwoon, and is owned by many of the core members of this association. Typical of many Kwoons across the globe, there are images of the master and discipline, larger photographs of seminars in which Li conducted, as well as the lineage chart that shows the links between Grandmaster Ip Man and his forbearers and the current generation of students learning under Sifu Bridge. We can see from this scenario that beginning students are welcomed into the group and are quickly socialized into the rules and cultural expectations far removed from the contemporary, legally-recognised familial relations just a few metres outside the front door. Regardless of their own ages and origins, students must call a white working-class British man in his early forties 'Sifu' (teaching father) and must refer to his seniors in reverential tones. In order to stay and thrive in the group, they should conceive of their fellow students as brother and sisters, and play a role in nurturing the juniors in the school. Dave, one of the up-andcoming intermediate students in the group, explained his viewpoints on the direct lineage and immediate family akin to a Buddhist monastery:

I see it in the same way that I see things like Buddhist monks and stuff like that. They see themselves like a family. They have a master, and their master has a master, and their master has a master. And it goes back hundreds and hundreds of years. Even the enlightened beings have masters who they revere, and those masters have masters have masters who they revere. And it just goes on in a long chain through history. It feels like you're part of something big. (Dave, Wing Chun practitioner).

These extensive family trees in TCMA sometimes do occasionally stem back across the centuries, although Chinese martial arts have many legendary tales of mythical founders and undocumented earlier history (Green \& Svinth, 2003). Nevertheless, despite perceived shared ancestors among practitioners across schools, it is the direct master that heads up a particular lineage that can make a significant difference in the art. Dave's own teacher, Sifu Bridge, reflected on his master's unique approach to the art:

Wing Chun is based on interpersonal relationships, and is therefore down to personal interpretations. From the cage fighting of Tony Jones to a more scientific approach, no one does Wing Chun in the same manner. No one does Wing Chun as Sifu Li. (Sifu Bridge, Wing Chun instructor). 
As a head of his own school (and nuclear family) in Britain, Sifu Bridge has set up a full-time headquarters in a converted chapel that has formed a base for his operations for over two decades. For many other practitioners worldwide, such Kwoons are perceive as a place home from home, yet one with guarded gates, as disclosed in the next subsection of our analysis focusing on metaphors of house and home.

\title{
5.2 School is home
}

The Kung Fu family is in fact a well-organized and normally inclusive social group, but to get inside is not always easy. Starting the training and becoming a fresh junior may not bring the same benefits as the senior members possess. For example, some teaching material, skill or forms may not be available for juniors, and much deeper knowledge is reserved for long-term and advanced students (see also Nulty, 2017). In the following paragraph, an interviewee, Karl, used the metaphor of closed door to describe concepts open only for senior practitioners and also why (in his opinion) high ranking members, such as highly skilled teachers, should train only behind the closed door. He uses the door metaphor to separate both people and the content of training:

\begin{abstract}
We have something we consider closed door forms. Some forms that people won't see in public. There are two reasons for it. First, one is the martial art, because years ago people used Kung Fu styles to fight each other. They didn't want you to see what they could do. But the most important reason for me is they wouldn't show it because it would discourage their own students. So if you're not training for so long and see someone so powerful to you, it can have negative effect. You think, 'Oh God, I'm never gonna be able to achieve this', and you may leave the school. So this is why a lot of Sifus do individual training on their own. Because the students may think the gap is too big. There are only some very senior masters, who can train together but really we shouldn't mix very senior people with very junior people. It's not good. You can mix advanced with junior because they can learn something, but the expert level should really train together behind the closed door. (Sifu Karl, Long Jing instructor).
\end{abstract}

The resulting aspect of such an arrangement is that the juniors remain under influence of the senior members, which could be understood a form of control. Here, an introduction is used to explain the fragile strategy how to cope with the control the community had over him. Karl further explained that he could learn from his senior in Hong Kong because he was introduced to him through his own teacher, and therefore there was no conflict of interests. He justified the necessity of such act of respect:

Veronika: Does your previous teacher need to be worried that you are skipping him?

Karl: No, because it was done right. Once you have the respect, that's what needs to be done, the introduction, you always have to respect, you can't just jump from one Sifu to another Sifu. It's disrespectful. It has to be your master who would tell anyone else to teach you. Be respectful with your previous Sifu. You've got to make the introduction and it's got to be an agreement.

(Sifu Karl).

Introduction or reference commonly served as guides for the metaphor of getting inside the tight social group, which was sometimes even compared to clans by some participants. The same interviewee as above told Veronika about his experience when meeting with his Hong Kong-based teacher for the first time. Again, he used the metaphor of introduction, which does not necessary mean being introduced directly to someone with shaking hands, but simply informing the school that you are coming with the consent of your previous teacher or when both sides started the communication prior to accepting the student:

Veronika: Could you meet him without the introduction?

Karl: No. You have got to get introduced. If I came over here and just asked around where is the nearest school, you can't just walk in, they won't teach you. The Chinese can be quite secretive, or it depends on what you look like. And some people say, it can be quite clannish or even some people say they can be racist towards white people.

(Sifu Karl). 
Another participant, Sifu Greg, remembered his experience with a similar situation in San Francisco's Chinatown, when a reference basically opens the door for the student:

It all depends on the reference. Who is referencing you. They ask you, why do you want to practice? You say, my granny sent me. What?! Who is your granny? Ah! Then you are welcome, come inside... (Sifu Greg, Taijiquan and Tang Lang instructor).

It is clear from the citation that the group and especially its seniors pose a certain kind of power. A female participant marked the Sifu of the school as gatekeeper, to illustrate that the seniors are those who keep the knowledge and, in congruence to the above citations, dose it carefully to the students. One informant explained this hierarchy based on age and hierarchy: "They have the school in Hong Kong and it is still in the hands of a family. The current gatekeeper is already over 70 years old."

\subsection{Club is nuclear family}

The similarity with biological families signifies not only a parent-child relationship, but also safety and support in the group. Metaphors such as lighthouse, oasis, island or solid rock appeared to describe how secure the participants feel among their Kung Fu family and the strong sense of belonging it provides them with. In the next citation, Greg, a European who has now relocated to a Chinatown in the USA, described how the Kung Fu community replaced the closeness of the family he lost:

Greg: For me, it replaced my family, that I didn't have in USA. I did not have anyone there. My Sifu was like my father, my classmates like brothers.

Veronika: Is the community important?

Greg: Incredibly important. It is the oasis, an island in life where you can resort, go, find refuge, avoid the reality. And there are people that make you feel good, make you feel good.

(Sifu Greg).

Another practitioner of a different style, Frank claimed the following on his 'place' in the 'family home':

Frank: They see me as one of them.

Veronika: How do you know?

Frank: Because of the way they treat me. They treat me like a family member and they treat me quite well, and they call me 'Western Chinese.' That's where I am. I'm a family member.

(Frank, Hung Kuen practitioner).

This indicates that the speaker believes his position is inside the Kung Fu circle. The connection and the strong bond among the members of the community is one of the characteristics expressed by the family metaphor. In the next citation, our key informant Karl says that the financial situation or social status of the members play no role, as when he comes to Hong Kong for a visit, his Kung Fu family comes down to see him:

Most of the guys in the in my school, are actually close to millionaires, yeah. Very successful businessmen. But once I come, they all take the time off to meet me. So, it's a good family, a good sense of community. (Sifu Karl).

\subsection{Teacher is father}

This community mentioned by Greg, Frank and Karl subsection has a clear leader: The teaching-father or Sifu that leads the everyday teaching and training activities of the school. One practitioner recalls his first engagement with his own Sifu across language barriers when he first moved to Hong Kong:

It's unbelievable. On the day we met in 2007, we couldn't understand each other. He didn't even speak English, I didn't speak Cantonese at all. And from that day on, I was like a son to him. So all the family parties? I was invited to go there, everything. He really took care of me like I was a son. 
At first, that was strange, because it's not European, but even today, he's still doing that. He is like a father. He is Sifu. Many people call their Sifu 'master.' Mainly Europeans, I would not do that because he is Sifu, that includes fu-father. (Sifu Colin, Bak Mei instructor).

As illustrated with the Colin's words, the expression of son or father shows a strong connection between the members of the Kung Fu group, which the interviewee compares to the biological family. The family members' labels mark clearly the line between the insiders and outsiders in the terms of membership in the group. It also expresses certain significance of the community for the interviewees, as well as significance of their membership in this Kung Fu family.

To point out the relationship with his teacher, Karl also used a metaphor of father. But this time not only when referring to himself as a student, but also to show the responsibility and expectations when being a teacher. Using the term father, he could explain quickly and clearly the wide range of scope of the Sifu, aiming to illustrate that it is not only a coaching or a teaching persona, but people look up to the Sifu as to their mentor, very similarly as they would to their own parent:

When you become a Sifu as well, because in Kung Fu there is the community or the family, they almost see you as the father figure. So, if they have a problem in life, they come to you. You gotta take off all the baggage. I could be anything! Financial coach, relationship coach... (Sifu Karl). mused:

In a similar vein, Sifu Bridge, the patriarchal figure in George's ethnography, recently

Sifu means father; therefore, as a father it means not to cheat to you. I would never cheat my old man; I would never lie to my own. I have to be totally honest for you to mature and grow. (Sifu Bridge).

Personal relationships based on a parent-child model, is therefore the core of the Kung Fu community. Another topic opened was the clossenes or the distance in the relationships in the Kung Fu family, by which they described a necessary distance from their student (in mark of respect and position) but also a cherished closeness in the sense of informality and playfulness in training. All the members are in the connection with each other, finding themselves having a firm place in this network. The community provides its members a safe, supportive atmosphere, similar to a biological family with intra-generational relationships between siblings.

\subsection{Classmates are siblings}

In these excerptions explored so far, male labels have appeared, with the term son but not daughter. There were only five women in our collective sample (a representational one considering the continued dominance of men in this physical culture), and the women did not label themselves as daughters. However, the women in this research worked with the metaphor of family in the same way as their male classmates and contemporaries. In this citation, a female interviewee explained her feeling of belonging:

Barbara: Sifu, he has this way of getting to know you and developing his kind of family. You're calm, you stand, you're warming up and he just walks past you, pulls your hand up. And, with your eyes closed, having someone pulling my middle finger, it's funny.

Veronika: What kind of message is it?

Barbara: It is ok for you to be here, which is nice. You no longer get the foreigner treatment.

(Barbara, Taijiquan practitioner).

Elsewhere, Tony, a practitioner in Bridge's school, emphasizes the physical risk involved in Kung Fu training, and the moral imperative of caring for one's peers or 'brothers':

You're training really dangerous stuff, being able to kill people, strikes to the throat, and you're trusting each other, and you're training to touch. Not to hurt the person, because he is your brother. It's like you don't hurt the person who's helping you on your path and to do your training. We don't try to hurt each other at all. The art is not to hurt your brother. But do the techniques so 
you are actually practising it real. You need to touch. There's no point in practising two inches away. Cos if you have a fight, you might fucking miss by two inches (laughs). (Tony, Wing Chun practitioner).

The Kung Fu family has an inner structure and hierarchical levels of membership. The teacher logically stands on the higher level than the student, and so do the senior practitioners. As the whole group is built in a family-like structure, those who are at the same level are perceived as Kung Fu brothers and sisters. Those are the classmates, the common students of the same teacher, as one interviewee expressed: "We call ourselves brothers, sisters. Traditionally, I respect my Kung $\mathrm{Fu}$ brother who is practicing longer than me." Thus, even among the classmates there exists a hierarchical order. Interestingly, this distribution is not based on the skills of the students, but in fact on the day they became members of the school. In the following quotation, an interviewee explains this using the metaphor of placing, place:

The placing in the school is at the moment you come to the school, date, that is your place in the school. There are people who came before you, that is the structure and than you have people who came after you, so it works like that. Somebody is older than me, but his technique is not so good, but he is my older Kung Fu brother, so I have to listen to him. (Martin, Hung Kuen practitioner).

The metaphor of placing describes assigning a student his status in the group, based on his initiation of the training. Everybody start as the most junior members of the group and with new students entering the school, their status moves slowly up. From the beginning, the members find themselves in the middle of a network, with a firm place, and being connected both to the senior and junior members of the Kung Fu family. To differentiate the Kung $\mathrm{Fu}$ family from other group structures, Karl used the meaning of hierarchy in terms of inequality to show that Kung Fu family members are all equally important, conversely for example an arrangement where lower level members are less significant:

The culture is for my style not really a hierarchy. Everybody is considered the same. So, the philosophy behind it is everybody is equal, just have some different start and are at a different part of their journey. And the thing is, in your lineage you are always linked to your Sifu. And even he is dead, even you don't like him. Doesn't matter, you are always linked to your Sifu. (Sifu Karl).

\subsection{Kung Fu is relationship}

From Karl's account, it seems that the teacher-student relationship is not just a lifelong pledge of loyalty, but remarkably, one that continues after the teacher's passing. In the final section of the analysis, which draws together the components of family, we show relationships as one of the main characteristics of learning Kung Fu. A male participant spoke about the situation when a student decides to leave or change the Kung $\mathrm{Fu}$ school and marked Kung $\mathrm{Fu}$ as a personal relationship. In his experience, switching schools has to be communicated with both sides, and the student should ask for a permission first.

Lars: I think it's a general sense. Like you if you have a boyfriend and you wanna break up with him, I think you should talk about it. Not separate and 'bye bye.'

Veronika: Can you compare it?

Lars: Yeah, because it's a relationship. If you go there every day for many years and stay with the people for a long time, then they are not just your classmates, they are your friends and the teacher is also your friend. If you have a reason to go and you are willing to tell them, you should explain why. I think one point is, Kung Fu is a special relationship.

(Sifu Lars, Bak Mei instructor).

Based on this debate, later in the interview, we again touched on this topic, when discussing the cooperative nature of the community, as opposite to being competition oriented:

The Kung Fu is the last thing we want to compete in. Too much pressure. You don't see the people as often and the relationship is maybe even better because you treasure the relationship. (Sifu Lars). 
This is consistent with the previous section when Kung $\mathrm{Fu}$ family (and the Kwoon in particular) represents a supportive and safe place akin to a home. People may come from a different work or school environment, where they need to compete and to prove their superiority, and this interviewee noted how soothing it is when he does not have to compete with others any more.

Still, the Kung Fu family appears to have a firm structure with different levels. In the next quotation from Martin, domino is employed as another metaphor to described how learning is passed from the senior to junior members:

You cannot learn kung fu by yourself. It is an interaction with other people. My older fellow students, they teach me, they give me more instructions than the teacher himself. The teacher teaches the older students, those under him, it's like a domino. (Martin).

Kung $\mathrm{Fu}$, according to these accounts, can be understood not only as a family, but as a broader set of relationships. This may start with ancestors in the system to lineage holders whose portraits hang on the walls of Kwoons. The direct relationship exists on a communal basis with the immediate family of the Sifu and Kung Fu siblings, but all in the effort to conserve the quality and teachings of previous generations and pass it on for future generations of those entering the door of their potential new home, the Kwoon.

\section{Conclusion: Metaphors of belonging across time and place}

This exploratory article sought to highlight and deconstruct the subcultural ideal of 'Kung Fu family' as a conceptual metaphor (KUNG FU IS FAMILY) through the theoretical framework of the Contemporary Theory of Metaphor (Lakoff \& Johnson, 1980, 1999). As a collaboration between a phenomenological psychologist and an anthropological sociologist using two extensive qualitative data sets, we used this theory and its corresponding metaphor analysis for their rich insight into qualitative data and their cross-disciplinary possibilities. We hope this venture, has contributed to knowledge of a key metaphor in TCMA - one that guides the way of thinking about the art, its history, its future and the interconnections between the immediate practitioners and people far and wide, as our international (Veronika's) and regional (George's) samples indicate. Our core argument is that this conceptual metaphor - a way of thinking and feeling (and therefore) acting about Kung Fu in terms of family - provides a deep sense of belonging for people from a plethora of backgrounds. Although Kung Fu might have once been the preserve of ethnic Chinese and for clans practicing genealogy in their native villages (Wile, 2018), it is now an open art undergoing change at the hands of Western practitioners, Sifus and innovators. We accounted for this past in the introduction, and then explored the way of conceptualizing Kung Fu through the six elements of: a) Family tree (LINEAGE IS FAMILY TREE); b) The place (SCHOOL IS HOME); c) The community (CLUB IS FAMILY); d) teacher-student relationships (SIFU IS FATHER); e) peer relationships (CLASSMATES ARE SIBLINGS), and f) the broader interconnections (KUNG FU IS RELATIONSHIP). Seen in this guise, the Kung Fu exponents belong in their Kwoon or club, but also belong to wider group composed of distance cousins, recent seniors and forbearers and also ancestors. The fellow students are seen as siblings, while there is a sense of responsibility to pass on the art to the next generation and nurture the younger generation on incomers. All of these form vital parts of the conceptual metaphor and the metaphorical linguistic expressions we stressed in our analysis.

As outlined in the introduction, 'Kung Fu', as the genetic (and modern) term for TCMA, is now practiced around the world. Kung Fu, being a concept, is not a family per se, but Kung Fu associations can act in this manner. The many federations and societies operate across cities, cultures and continents, and can form links between a diverse group of people of different ages, ethnicities and professions. It is no longer the preserve of Chinese ethnic groups and secret societies (Farrer, 2018), although power and knowledge does remain in Chinese homelands and areas in the Chinese diaspora, such as Singapore (Farrer, 2011), and, as our article indicates, Hong Kong. It is also a core metaphor for identity in Northern China, where it is tied to village locality and origin (see Zhang \& Green, 2012). The work of Guodong, Green and Gutiérrez-García (2016, p. 26) have recently revealed this phenomenon: 
The fundamental reason for Meihuaquan's revival is that it cultivates the sense of group identity for local people in northern China. This kind of group identity is not only about social relationships, but also spiritual life; not only accepted by males, but also recognized by females; not only felt by older people, but also supported by the younger generation; not only favored by peasants, but also practiced by college students.

In the West (and for Western practitioners), the picture remains quite different in the sense that it is not tied to a locality or land, although the Kung Fu family exists in a similarly inclusive fashion across age, gender and social class. Kung Fu remain unregulated in the martial arts industry and general sporting governance, unlike the Japanese martial arts, for instance. Instead, the associations are historically structured along embodied (yet largely male) lineages in which intergenerational contact and considerations of past and present practitioners are imperative. The conceptual metaphor of KUNG FU IS FAMILY (extending the member-identified term of Kung Fu family) has been useful in deconstructing the organisation of the martial art and the meanings that the practitioners themselves give to the art, their practice and their relationships with their Kung $\mathrm{Fu}$ kin. However, it is important to note that these lineages of embodied knowledge, or 'body lineages' as Brown and Jennings (2011) put it, seen here as 'family trees' are simplified maps of linear knowledge transmission. In reality, Western teachers like Sifu Bridge have in fact learned from a number of other masters in his own country prior to finding Master Li and pledging loyalty and oaths to him as a transatlantic disciple.

Simply put, the metaphor of family helps us understand the meaning (within and across practitioner 'generations') behind the longstanding physical cultures and their continuity across time (from centuries to mere decades) and space (from moving across regions of a country to crosscontinental allegiances). The Kung Fu family is, of course, an idealized type of organization with points for critique in daily reality. In a positive manner, it permits the TCMA to operate as alternative organisations based on lifelong practice and cooperate development. These historical physical cultures have much to teach sport, but can also learn from them, as Wushu and other sporting formats of Kung Fu develop. Such a metaphor, when critically appraised, can help appreciate a unique physical culture and question what is more familiar to us, such as politicised discourse of nations and football teams as being families, including FIFA's 'football family' and the 'IOC family' from international governing bodies.

In this sense, when seen as a family, these associations, groups and clans are pertinent for social scientists looking as the sense of belonging across time and place. Future research into the TCMA, and the southern styles in particular, could use this metaphor as a basis for further analysis of knowledge transmission, power dynamics, internationalisation, modernisation and other important social processes. Meanwhile, conceptual metaphors of Kung Fu family can help us understand the organisation and logics of TCMA practice, but might also help us question the common notions of the family itself. The well-established scholarship in the anthropology and sociology of the family (e.g. Ebaugh \& Curry, 2000; Kim, 2009) in particular might glean insights from this study and its analysis of a disparate group of martial artists who find meaning in their lives and a sense of belonging in an adoptive family far removed from their ethnic and social origins as (mainly) white Europeans and Westerners. Like many exploratory studies, more questions are raised than answers provided. Anthropologists and sinologists might explore these particular groups and ask: Are these groups really families or fictive-kinship groups, or is this just a metaphor? Sociologists examining the aspects of globalisation and modernisation might find this a pertinent case study. Following Giddens (1991), for example, what can the Kung Fu family teach us about what a family and self-dentity and personal projects can be in the late modern age? Some closing and rather poignant words from Sifu Bridge help us consider and revisit the sharing, caring and solidarity given when belonging to a Kung Fu family, and perhaps an idealised family in general. After returning to the association headquarters of Church Kwoon following several years of absence due to living overseas, George questioned his old teacher on the notion of Kung Fu family:

This is how you add your part of the collective around you. No one person is more important than anyone else. Hence you learn from your students. Your understanding of what you're doing and the transcendence of another person becomes greater. And you only learn through mistakes...The greater you become, the greater I become. It's like that in Wing Chun...Only through selflessness can we have greatness. (Sifu Bridge). 


\section{Acknowledgements}

Many thanks are due to our participants who helped form the invaluable data for the article. David Brown provided useful comments on an earlier version of this article, and Colin McGuire provided insights into the linguistics and culture of Kung Fu family.

\section{References}

Allen, B. (2013). Games of sport, works of art, and the striking beauty of Asian martial arts. Journal of the Philosophy of Sport, 40(2), 241-254. doi: 10.1080/00948705.2013.785418

Alter, J. (1992). The wrestler's body: Identity and ideology in North India. Berkeley, CA: University of California Press.

Bowman, P. (Ed.). (Forthcoming). Martial arts studies: A reader. London: Rowman \& Littlefield.

Bowman, P. (2015). Martial arts studies: Disrupting disciplinary boundaries. London: Rowman \& Littlefield.

Brown, D. (2016). Taoism through Tai Chi Chuan: Physical culture as religious or holistic spirituality? In M. de Souza, J. Bone and J. Watson (Eds.), Spirituality across disciplines: Research and practice (pp. 317-330). New York: Springer.

Brown, D., \& Jennings, G. (2011). Body lineage: Conceptualizing the transmission of traditional Asian martial arts (in the West). Staps, 32(93), 61-71.

Brown, D., \& Jennings, G. (2013). In search of the martial habitus: Identifying dispositional schemes in Wing Chun and Taijiquan. In R. Garcia Sánchez \& D. Spencer (Eds.), Fighting Scholars: Habitus and ethnographies of martial arts and combat sports (pp. 33-48). London: Anthem Press.

Brown, D., Jennings, G. \& Sparkes, A.C. (2014). Taijiquan the 'Taiji World' way: Towards a cosmopolitan vision of ecology. Societies, 4(3), 380-398. doi: 10.3390/soc4030380

Brown, D., \& Johnson, A. (2000). The social practice of self-defence martial arts: Applications for physical education. Quest, 52(3), 246-259. doi: 10.1080/00336297.2000.10491713

Channon, A., \& Jennings, G. (2013). The rules of engagement: Negotiating painful and intimate touch in mixed-sex martial arts. Sociology of Sport Journal, 30, 487-503. doi: 10.1123/ssj.30.4.487

Channon, A., \& Phipps, C. (2017). 'Pink gloves still give black eyes': Exploring 'alternative' femininity in women's combat sports. Martial Arts Studies, 3, 24-37. doi: 10.18573/j.2017.10093

De Campos Rosario, C., Stephens, N., \& Delamont, S. (2010). 'I'm your teacher! I'm Brazilian!': Authenticity and authority in European Capoeira. Sport, Education \& Society, 15(1), 103-120. doi: $10.1080 / 13573320903461061$

Domaneschi, L. (2016). Boards don't hit back: Ethnography of the practice of Wushu Kung Fu. Etnografia e Ricerca Qualitativa, 3, 473-496. doi: 10.3240/85153

Downey, G. (2004). Learning capoeira: Lessons in cunning from an Afro-Brazilian martial art. Oxford: Oxford University Press.

Ebaugh, H. R., \& Curry, M. (2000). Fictive kin as social capital in new immigrant communities. Sociological Perspectives, 43(2), 189-209. doi: 10.2307/1389793

Evans, B., Eys, M., \& Wolf, S. (2013). Exploring the nature of interpersonal influence in elite individual sport teams. Journal of Applied Sport Psychology, 4, 448-462. doi: $10.1080 / 10413200.2012 .752769$

Evans, M.B., Eys, M.A., \& Bruner, M.W. (2012). Seeing the "we" in "me" sports: The need to consider individual sport team environments. Canadian Psychology/Psychologie Canadienne, 53(4), 301-308. doi: 10.1037/a0030202

Farrer, D. S. (2011). Coffee-shop gods: Martial arts of the Singapore diaspora. In D.S. Farrer and J. Whalen-Bridge (Eds.), Martial arts and embodied knowledge: Asian traditions in a transnational world (pp. 203-229). Albany, NY: SUNY Press.

Farrer, D. S. (2018). Captivation, false connection and secret societies in Singapore. Martial Arts Studies, 5, 36-51. doi: $10.18573 /$ mas.48

Flowers, P. Larkin, M., \& Smith, J. A. (2009). Interpretative phenomenological analysis: Theory, method and research. London: SAGE Publications Ltd.

Frank, A. (2014). Unstructuring structure and communicating secrets inside/outside a Chinese martial arts association. JOMEC Journal, (5). doi: 10.18573/i.2014.10269 
Frank, A. (2006). Taijiquan and the search for the little old Chinese man: Understanding identity through martial arts (1st ed.). Basingstoke: Palgrave Macmillan.

Giddens, A. (1991). Modernity and self-identity: Self and society in the late-modern age. Cambridge: Polity Press.

Girton, G. D. (1986). Kung fu: Towards a praxiological hermeneutics of the martial arts. In H. Garfinkel (Ed.), Ethnomethodological studies of work (pp. 60-91). London: Routledge.

Green, K. (2011). It hurts, so it is real: Sensing the seduction of mixed martial arts. Cultural and Social Geography, 12(4), 377-396. doi: 10.1080/14649365.2011.574796

Green, T. A. \& Svinth, J. R. (Eds.). (2004). Martial arts in the modern world. London: Praeger.

Guodong, Z., Green, T. A., \& Gutiérrez-García, C. (2016). Rural community, group identity and martial arts: Social foundation of Meihuaquan. IDO Movement for Culture. Journal of Martial Arts Anthropology, 16(1), 18-29. doi: 10.14589/ido.16.1.3

Jennings, G. (2014). Transmitting health philosophies through the traditionalist Chinese martial arts in the UK. Societies, 4(4), 712-736. doi: $10.3390 /$ soc4040712

Jennings, G. (2010). Fighters, thinkers and shared cultivation: Experiencing transformation through the traditionalist Chinese martial arts. Unpublished doctoral thesis, University of Exeter, UK.

Jennings, G., Brown, D., \& Sparkes, A. C. (2010). "It can be a religion if you want": Wing Chun Kung $\mathrm{Fu}$ as a secular religion. Ethnography, 11(4), 533-557. doi: $10.1177 / 1466138110372588$

Judkins, B., (2014). Inventing Kung Fu. JOMEC Journal, (5). doi: 10.18573/j.2014.10272

Judkins, B., \& Nielson, J. (2016). The creation of Wing Chun: A history of the southern Chinese martial arts. Albany, NY: Press.

Kennedy, B., \& Guo, E. (2010). Jingwu: The school that transformed Kung Fu. Berkeley, CA: North Atlantic Books.

Kennedy, B., \& Guo, E. (2005). Chinese martial arts training manuals: A historical survey. Berkeley, CA: North Atlantic Books.

Kim, E. C. (2009). 'Mama's family': Fictive kinship and undocumented immigrant restaurant workers. Ethnography, 4, 497-513. doi: $10.1177 / 1466138109347000$

Lakoff, G. (1992). The contemporary theory of metaphor. In A. Ortony (Ed.), Metaphor and thought (2nd edition) (pp. 202-251). Cambridge: Cambridge University Press.

Lakoff, G., \& Johnson, M. (1980). Metaphors we live by. Chicago: University of Chicago Press.

Lakoff, G., \& Johnson, M. (1999). Philosophy in the flesh: The embodied mind and its challenge to Western thought. New York: Basic Books.

Layton, C., Higaonna, M., \& Arneil, S. (1993). Karate for self-defense: an analysis of Goju-Ryu and Kyokushinkai Kata. Peceptual and Motor Skills, 77, 829-830. doi: 10.2466/pms.1993.77.3.829

Mroz, D. (2008). Technique in exile: The changing perception of taijiquan, from Ming dynasty military exercise to twentieth-century actor training protocol. Studies in Theatre and Performance, 28(2), 127-145.

Nulty, T.J. (2017). Gong and fa in Chinese martial arts. Martial Arts Studies, 3, 51-64. doi: $10.18573 / \mathrm{j} .2017 .10098$

Partikova, V. (in press a). Psychological collectivism in traditional martial arts. Martial Arts Studies.

Partikova, V. (in press b). Testing the model of mental toughness in the setting of Chinese martial arts. Asian Journal of Physical Education \& Recreation.

Pedrini, L. (2018). Muoversi come puligi colprire como compagni: Uno studio etnografico sull'organizzazione sociale della boxe popolare. Unpublished doctorate thesis, University of Milano-Bicocca.

Ryan, A. (2008). Globalisation and the 'internal alchemy' in Chinese martial arts: The transmission of Taijiquan to Britain. East Asian Science, Technology and Society: An International Journal, 2(4), 525-543. doi: 10.1215/s12280-009-9073-x

Samino, E., \& Masci, M. (1996). Politics in football: Metaphor in the discourse of Silvio Berlusconi in Italy. Discourse \& Society, 7(2), 243-269. doi: $10.1177 / 0957926596007002005$

Shields, D., \& Bredemeier, B. (2011). Contest, competition and metaphor. Journal of the Philosophy of Sport, 38, 27-38. doi: 10.1080/00948705.2011.9714547

Smith, J., A., \& Osborn, M. (2003). Interpretative phenomenological analysis. In J. A. Smith (Ed), Qualitative psychology: A practical guide to research methods (pp. 53-80). London: SAGE Publications Ltd. 
Smith, B., \& Sparkes, A. C. (2004). Men, sport, and spinal cord injury: An analysis of metaphors and narrative types. Disability \& Society, 19(6), 613-626. doi: 10.1080/0968759042000252533

Stewart, C., Smith, B. \& Sparkes, A. C. (2011). Sporting autobiographies of illness and the role of metaphor. Sport in Society, 14(5), 581-597. doi: 10.1080/17430437.2011.574358

Theeboom, M., \& De Knop, P. (1997). An analysis of the development of Wushu. International Review for the Sociology of Sport, 32(3), 267-282. doi: 10.1177/1012690297032003004

Triandis, H. C. (1995). Individualism \& collectivism. Boulder, CO: Westview Press.

Vlachos, E. (2015). The benefits of using traditional martial arts as an intervention programme for children with behavioural, emotional and social difficulties. Journal of Pedagogic Development, 5(2), 37-45.

Von del Lippe, G. (2002). Media image: Sport, gender and national identities in five European countries. International Review for the Sociology of Sport, 3-4, 369-394. doi: $10.1177 / 101269020203700306$

Wacquant, L. (2001). Whores, slaves and stallions: Languages of exploitation and accommodation among boxers. Body \& Society, 7(2-3), 181-194. doi: 10.1177/1357034X0100700210

Wang, G., Qiu, P. X., \& Bao, L. (2010). The "boxing type awareness" must be enhanced for rebuilding the school Wushu education system. Journal of Physical Education, 17(4), 95-98.

Wildish, P. (2000). The big book of chi. London: Thornsons.

Wile, D. (2018). Fighting words: Four new document finds reignite old debates in Taijiquan historiography. Martial Arts Studies, 4, 17-35. doi: 10.18573/j.2017.10184

Woodward, K. (2008). Hanging out and hanging about: Insider/outsider research in the sport of boxing. Ethnography, 9(4), 536-560. doi: 10.1177/1466138108096991

$\mathrm{Yu}, \mathrm{N}$. (2003). Chinese metaphors of thinking. Cognitive Linguistics, 14(2-3), 141-165. doi: $10.1515 / \operatorname{cog} l .2003 .006$

Zarrilli, P.B. (1998). When the body becomes all eyes: Paradigms, discourses and practices of power in a South Indian martial art. New Delhi: Oxford University Press.

Zhang, Z. (2014). The art of Chinese kung-fu. Berkeley, CA: Gingko Press.

Zhang, G., \& Green, T. (2012). Introducción al boxeo de la flor del ciruelo: historia, cultura y práctica. Revista de Artes Marciales Asiáticas, 5(2), 21-44. doi: 10.18002/rama.v5i2.109

\section{Author's biographical data}

Veronika Partikova (Czech Republic) is a PhD candidate at the Hong Kong Baptist University, Department of Physical Education. She focuses on the traditional Chinese martial arts and their influence on European practitioners. Her research bridges psychological collectivism and mental toughness with Kung $\mathrm{Fu}$, and compares the training outcomes of traditional styles with modern Wushu. To do so, she applies a mixed methods approach, using the Interpretative Phenomenological Analysis and SEM modelling. E-mail: vpartikova@gmail.com

George Jennings (UK) is qualitative researcher interested in martial arts cultures, pedagogies and philosophies. He teaches at Cardiff Metropolitan University, and has lectured at universities in England, Scotland and Mexico. His work has examined the subculture of Wing Chun Kung Fu, the life experiences of practitioners of Chinese martial arts and the emerging Mexican system of Xilam as part of a nationalist movement. An advocate of practitioner engagement and qualitative methodology, George is academic consultant for DojoTV and is co-founder of the Documents Research Network (DRN). E-mail: gbjennings@cardiffmet.ac.uk 